\title{
Clinical Pharmacokinetics of Daptomycin
}

2 Nicolas Gregoire ${ }^{1,2}$, Alexia Chauzy ${ }^{1}$, Julien Buyck ${ }^{1}$, Blandine Rammaert $^{1,3}$, William

\section{Couet $^{1,2^{*}}$ Sandrine Marchand ${ }^{1,2}$.}

4

$5{ }^{1}$ INSERM, U1070, UFR de Médecine Pharmacie, Université de Poitiers, 1 rue Georges

6 Bonnet, TSA 51106, 86073 Poitiers Cedex 9, France

$7 \quad{ }^{2}$ Laboratoire de Toxicologie-Pharmacocinétique, CHU of Poitiers, 2 rue de la Miletrie, 86000

8 Poitiers, France

$9{ }^{3}$ Service de maladies infectieuses et tropicales, CHU of Poitiers, 2 rue de la Miletrie, 86000

10 Poitiers, France

11

12

$13 \quad *$ Corresponding author. william.couet@ univ-poitiers.fr, tel: (33) 549454379

14

15

16

17

Acknowledgments

18

No sources of funding were used for this review. The authors have no conflicts of interest

19 related to this review. 
2 Due to the low level of resistance observed with daptomycin, this antibiotic has an important

3 place in the treatment of severe Gram-positive infections. It is the first in class of the group of

4 calcium-dependent, membrane binding lipopeptide. It is a cyclic peptide constituted of 13

5 amino acids and a n-decanoyl fatty acid chain. The antibacterial action of daptomycin requires

6 its complexation with calcium.

7 Daptomycin is not absorbed from the gastrointestinal tract and needs to be administered 8 parenterally. The distribution of daptomycin is limited (volume of distribution of $0.1 \mathrm{~L} / \mathrm{kg}$ in 9 healthy volunteers) due to its negative charge at physiological $\mathrm{pH}$ and its high binding to 10 plasma proteins (about 90\%). Its elimination is mainly renal, with about $50 \%$ of the dose 11 excreted unchanged in the urine, justifying dosage adjustment for patients with renal 12 insufficiency. Pharmacokinetics of daptomycin is altered under certain pathophysiological 13 conditions, resulting in high inter-individual variability. As a result, therapeutic drug 14 monitoring (TDM) of daptomycin may be of interest for certain patients such as intensive care 15 unit (ICU) patients, patients with renal or hepatic insufficiency, dialysis patients, obese 16 patients or children. A target for the ratio of the area under the curve to the minimum 17 inhibitory concentration (AUC/MIC) greater than 666 is usually recommended for clinical 18 efficacy, whereas in order to limit the risk of undesirable muscular effects the residual concentration (Cmin) should not exceed $24.3 \mathrm{mg} / \mathrm{L}$.

21 Key points:

22 Daptomycin is highly bound to plasma proteins (90\%) and it's unbound fraction may vary 23 considerably between patients with strong impact on its pharmacokinetics. 
1 This protein binding of daptomycin should be considered for patients with renal failure,

2 including dialysis patients, as well as children. 


\section{$1 \quad 1$ Introduction}

2 Daptomycin is the first calcium-dependent membrane binding lipopeptide. It was isolated in

3 the 1980s, and found to have impressive activity against Gram-positive, but not Gram-

4 negative bacteria. [1] However, Eli Lilly and Company (Lilly) suspended clinical

5 investigation of daptomycin in 1991 because of skeletal muscle toxicity observed at high

6 doses (4 mg/kg every 12h). [2] In 1997, Cubist Pharmaceuticals, Inc. (Cubist) licensed

7 worldwide rights for daptomycin from Lilly. Yet due to the emergence of multidrug resistant

8 bacteria, daptomycin was revisited. Its side effects were minimized by changing its dosing

9 regimen and it received approval from the U.S. food and drug administration (FDA) in 2003.

10 Initial FDA authorization was for complicated skin and skin structure infections (cSSSI) in

11 adult and paediatric patients > 1 year old, and Staphylococcus aureus bloodstream infections,

12 including those with right-sided infective endocarditis in adults. Due to low resistance rate,

13 low frequency of side effects and convenient once-a-day administration, daptomycin is

14 currently widely used for Staphylococcus spp. and Enterococcus spp. infections. [3]

152 Chemistry

16 Daptomycin is produced as a minor component of a complex lipopeptide mixture by the soil

17 actinomycete Streptomyces roseosporus. [4] It is a cyclic peptide constituted of 13 amino acids

18 and a n-decanoyl fatty acid chain at the N-terminus with a $1620.7 \mathrm{~g} / \mathrm{mol}$ molecular weight

19 (Figure 1). It has 4 acids residues $\left(\mathrm{pK}_{\mathrm{a}}\right.$ of 1.3, 3.8, 4.1 and 4.4) and 2 basic residue (pK $\mathrm{pK}_{\mathrm{a}}$ of 1.3

20 and 10.7), resulting in a total molecular charge of -3 at neutral $\mathrm{pH}$ (the basic residue with $\mathrm{pKa}$

21 of 1.3 is unionized at neutral $\mathrm{pH}) .[5,6]$. The negative charge at neutral $\mathrm{pH}$ contributes to its

22 high solubility in water $(17.3 \mathrm{mg} / \mathrm{L}, \log \mathrm{P}=-5) .[7,8]$ and its lipophilic tail contributes to its

23 amphiphilic character. As a result of its negative charge, daptomycin aggregates into 
1 oligomeric structures with calcium, which enables the interaction of the lipophilic tail of

2 daptomycin with the bacterial cell membrane, a prerequisite of its antimicrobial activity [5].

\section{$3 \quad 3 \quad$ Mechanism of action}

4 Daptomycin is a membrane-active peptide active against Gram-positive bacteria.[9] The

5 presence of calcium ions at physiological concentrations $(1.25 \mathrm{mM})$ is a prerequisite for the antibacterial activity of daptomycin, by masking the overall negative charge and stimulating


8 affinity for negatively charged phospholids of cellular membranes, including 9 phosphatidylglycerol. Yet the exact mechanism of action of daptomycin is still debated, it is 10 admitted that it displays a rapid bactericidal activity by interacting with the cytoplasmic 11 membrane of the bacteria, leading to an efflux of potassium, which in turn should lead to 12 bacterial death.[11] However, the simple pore formation may not be the primary antibacterial 13 mechanism of daptomycin, and insertion into fluid membrane microdomains, so-called RIFs 14 (regions of increased fluidity), and subsequent rigidification of those regions seems to play a 15 central role. [9].

Furthermore, lipopeptides are known as immunomodulators that interact with pattern 17 recognition receptors such as Toll-like receptors in antigen presenting cells. Daptomycin can 18 also insert into membrane vesicles of immune cells, but further studies are needed to elucidate 19 this possible interaction based on the known immunomodulatory activity of other 20 lipopeptides. [12]

\section{Spectrum of activity.}

22 Daptomycin presents a rapid in vitro bactericidal effect against a wide spectrum of Gram23 positive bacteria including Staphylococcus aureus (SA, of which methicillin resistant 
1 Staphylococcus aureus, MRSA), coagulase-negative staphylococci, streptococci (of which

2 penicillin-resistant streptococci), enterococci (of which vancomycin resistant enterococci,

3 VRE), Peptostreptococcus, Clostridium perfringens and corynebacterium sp. [13]

\section{Mechanisms of resistance}

5 The prevalence of de novo resistance to daptomycin without prior exposure has been reported

6 to be extremely rare $(0.04 \%$ in $S$. aureus $)$. $[14,15]$ However, even if daptomycin is still quite

7 active, resistance to daptomycin has been widely reported over the past years in Staphylococci

8 and Enterococci. Mutations of various genes are involved in these mechanisms of resistance,

9 e.g. increase of bacterial membrane positive surface charge, alteration in the bacterial

10 membrane fluidity, increased carotenoid pigment content, and increased teicoic acid synthesis

11 in the cell wall have been described [16] For more details, a review has described previously

12 the mechanisms and genes involved in resistance to daptomycin. [17]

13 Depending on the bacteria, two main mechanisms of resistance are used to develop resistance 14 to daptomycin. With Enterococcus faecalis the mechanism corresponds to diversion of the 15 antibiotic from the preferential binding site of daptomycin at the septum of the bacteria, 16 resulting in ineffective binding of daptomycin. With Staphylococcus aureus and Enterococcus 17 faecium, the mechanism is a modification of charge of the cell membrane leading to 18 electrostatic repulsion of the positively charged complex daptomycin- $\mathrm{Ca}^{2+}$. Noticeably with 19 Staphylococci, daptomycin resistance is generally observed in high-inoculum infections like 20 endocarditis and abscesses when insufficiently high low doses are used.[18-20] Furthermore, 21 the vancomycin-intermediate $S$. aureus (VISA) phenotype is also linked to increased 22 resistance to daptomycin during therapy. [21] This cross-resistance is likely induced by 23 modifications in the same molecular pathways. [17] 


\section{Indications approved in the marketing authorization}

2 Daptomycin is used to treat skin infections, bloodstream infections, right-sided endocarditis,

3 sepsis and urinary tract infections caused by Gram-positive bacteria, such as S. aureus, both

4 methicillin-susceptible and -resistant (MSSA and MRSA), as well as several Streptococcus

5 and Enterococcus species. [22]

\section{$6 \quad 7 \quad$ Pharmacokinetic/Pharmacodynamic indices and breakpoints}

7 It was shown that area under the curve/MIC (AUC/MIC) ratio is the

8 pharmacokinetic/pharmacodynamic (PK/PD) index that best correlates with daptomycin

9 activity.[23] According to target values used by the EUCAST to determine breakpoints,

10 AUC/MIC ratios needed for bacteriostatic or bactericidal effects are $>438$ or $>1061$. [24-26]

11 Although antimicrobial activity depends on unbound antibiotic concentrations, these targets

12 were estimated in mice with thigh infection and rely on total concentrations. Yet since the

13 average unbound fraction (fu) in mice and human are comparable (about 10\%), these targets

14 can be used in human. However because it is extensive, even a minor modification of 15 daptomycin protein binding may have a major effect on fu, which may therefore vary widely

16 between subjects or/and due to concentration dependent or disease related effect. [23, 27] This

17 protein binding issue could therefore possibly explain that in some cases no link was 18 established between PK/PD indices and clinical efficacy [28] while in other cases the link was 19 U-shaped [29]. Yet, in a clinical study with 35 patients, the ratio AUC/MIC>666 was 20 associated with statistically reduced mortality[30] and in another study, a residual total 21 concentration (Cmin) of less than $3.2 \mathrm{mg} / \mathrm{L}$ was associated with reduced efficacy. [31]. At that 22 point the clinical relevance of these target values based on total concentrations is not 23 guarantee. 
1 Clinical breakpoints have been fixed by EUCAST at $1 \mathrm{mg} / \mathrm{L}$ for Staphylococcus spp. and

2 Streptococcus spp. (except S. pneumonia for which the use of daptomycin is not

3 recommended). [32] The EUCAST did not determined clinical breakpoint for Enterococcus

4 spp. but determined epidemiological cut-off values of $4 \mathrm{mg} / \mathrm{L}$ for E. faecalis and $8 \mathrm{mg} / \mathrm{L}$ for

5 E. faecium, whereas the Clinical and Laboratory Standards Institute (CLSI) determined a

6 susceptible breakpoint of $<2 \mathrm{mg} / \mathrm{L}$ for E. faecalis and a separate susceptible dose-dependent

7 breakpoint of $<4 \mathrm{mg} / \mathrm{L}$ for E. faecium.[33]

8 Regarding toxicity, a total trough concentration (Cmin) of daptomycin $>24.3 \mathrm{mg} / \mathrm{L}$ was shown

9 to be associated with an increased probability of creatine phosphokinase (CPK) elevation. [2,

$103,34,35]$ However, for some authors this threshold could be exceeded without increasing the

11 risk of toxicity.[36]

\section{Bioanalysis}

13 Chromatographic Methods. Chromatographic methods for the determination of daptomycin 14 in plasma [27, 30, 37-41], dry plasma spots [40], serum [42], whole blood [43], urine [27, 37, 15 38], plasma ultrafiltrate [27], and peritoneal fluid [37] can be found in the literature.

Methods using UV detection have quantitation limits ranging from 2 to $5 \mathrm{mg} / \mathrm{L}[30,38,41$, 17 42], higher than those using mass detection with positive electrospray ionization, with quantitation limits ranging from 1 to $2 \mathrm{mg} / \mathrm{L}$ in plasma and of $0.05 \mathrm{mg} / \mathrm{L}$ in plasma ultrafiltrate. [27, 37, 39, 43, 44] Another characteristic of LC-MS/MS methods is that they allow the use of small test samples $(50 \mu \mathrm{L})$, which can be an advantage for concentrations

21 determinations in paediatrics.[44]

Stability. Because of temperature dependent proteases activity, daptomycin is unstable in serum at body temperature and decreases by more than $50 \%$ after only $24 \mathrm{~h}$. [45] However,

24 daptomycin is stable at room temperature in whole blood and in plasma for at least $2 \mathrm{~h}$ and $6 \mathrm{~h}$ 
1 respectively. [44] Concentration loss in serum at room temperature is approximately 5\% after

$212 \mathrm{~h}$ and more than $10 \%$ after $24 \mathrm{~h}$. [45] Concentrations in serum samples stored at $4{ }^{\circ} \mathrm{C}$

3 decrease by $10 \%$ after 7 days. [45] Daptomycin is stable in stock solution and in plasma for at

4 least one year at $-20^{\circ} \mathrm{C}$, it is also stable after 3 freeze/thaw cycles.[39, 42, 44] After

5 extraction, daptomycin is stable in auto-sampler at room temperature for at least $6 \mathrm{~h}$. [39, 44]

6 Protein binding estimation. Protein binding of daptomycin can be determined by

7 ultracentrifugation. [46], ultrafiltration [27], or microdialysis [47]. As daptomycin adheres to

8 ultrafiltration membranes, non-specific binding should be assessed. Furthermore non-specific

9 binding reported in the literature increases as concentrations decrease, ranging from $5 \%$ for 10 concentrations of $70 \mathrm{mg} / \mathrm{L}$ to $75 \%$ for concentrations of $1 \mathrm{mg} / \mathrm{L}$. This relationship between the 11 concentration of daptomycin and non-specific binding must be taken into account when 12 correcting the concentrations measured in the ultra-filtrates. [27, 47]

\section{Clinical pharmacokinetics}

\section{$14 \quad 9.1$ Dosage regimens approved in the marketing authorization}

It is indicated that daptomycin should be administered once daily as a 30-min infusion at a dose of $4 \mathrm{mg} / \mathrm{kg} /$ day (complicated skin and soft tissue infections) or $6 \mathrm{mg} / \mathrm{kg} / \mathrm{day}$ (other

17 indications). In case of renal insufficiency (creatinine clearance $<30 \mathrm{~mL} / \mathrm{min}$ ), the interval of 18 dose should be extended to $48 \mathrm{~h}$. At initiation of treatment, and then at least once weekly, CPK 19 levels should be measured in order to monitor the occurrence of muscular adverse events. [48]

20 EMA and FDA approved the use of daptomycin for treatment of paediatric patients with 21 complicated skin and soft tissue infections (cSSTI) at dosages of 5, 7, 9, and $10 \mathrm{mg} / \mathrm{kg}$ every $24 \mathrm{~h}$ for patients aged 12-17, 7-11, 2-6, and 1-2 years old, respectively [48, 49] and at dosages

23 of 7,9 , and $12 \mathrm{mg} / \mathrm{kg}$ every $24 \mathrm{~h}$ for patients aged $12-17,7-11$, and 1-6 years old, respectively 24 for treatment of $S$. aureus bacteraemia $[48,50]$. Due to peak concentration toxicity observed 
1 in preclinical studies, it is recommended to extend the infusion time from 30 min to 1 hour for

2 children under 11 years of age.[48-50]

\section{$3 \quad 9.2 \quad$ Absorption}

4 Due to its very low lipophilicity $(\log \mathrm{P}=-5)$, daptomycin is poorly absorbed orally with $>90 \%$

5 excreted in the faeces in animal models.[13] There is no clinical information about

6 subcutaneous administration but in animals a relatively high bioavailability was observed

7 using this route of administration. [13] Peritoneal, intrathecal or intraventricular

8 administration of daptomycin were also used. [51, 52]

\section{$9 \quad 9.3$ Distribution}

10 The extravascular distribution of daptomycin is limited due to its negative charge at 11 physiological $\mathrm{pH}$, its low lipophilicity and its high binding to plasma proteins. The volume of 12 distribution of total daptomycin is around $0.1 \mathrm{~L} / \mathrm{kg}$ for healthy volunteers.[53, 54].

13 Daptomycin is substrate of the efflux transporter p-glycoprotein (P-gp). [55] In patients $14(\mathrm{n}=81)$ with bone and joint infection, the volume of distribution of daptomycin was reported 15 to be $25 \%$ lower in individuals having the CGC/CGC haplotype for $p g p$ compared with any 16 other haplotype, which, according to the authors, could be due to a greater efflux of certain 17 tissues.[56] However, in another study conducted on 12 healthy volunteers, neither rifampicin 18 administration nor pgp single nucleotide polymorphism were associated with significant 19 differences in daptomycin disposition.[57]

20 Distribution within cells. In vitro, it has been shown that daptomycin can penetrate within 21 cells, with a $60 \%$ ratio between intracellular and extracellular concentration in neutrophils. $22[55,58]$ However, it was shown in mice that achievable plasma levels were insufficient to 23 eliminate an intracellular strain of MRSA. [59] 
1 Distribution into soft tissue interstitial fluid. After administration of daptomycin at $4 \mathrm{mg} / \mathrm{kg}$

2 it has been shown in healthy volunteers and diabetic patients that daptomycin diffuses into the

3 soft tissue interstitial fluid, with concentrations in the range of 70 to $90 \%$ of free plasma

4 concentrations. [47]

5 Distribution within lung. While daptomycin is effective against S. pneumoniae in vitro, this

6 does not translate in vivo into sufficient therapeutic activity for treatment of lung infections.

7 This may be due to a weak distribution of daptomycin in the lungs, but also to its

8 sequestration by lung surfactant, which contains phosphatidylglycerol..[60] For now,

9 information regarding lung distribution is missing.

Distribution within central nervous system. After IV infusion of daptomycin $10 \mathrm{mg} / \mathrm{kg}$ to

11 patients with meningitis, daptomycin has a minimal penetration into central nervous system

12 ( $<1 \%$ which was corrected to $11.5 \%$ after accounting for protein binding). [52, 61] By

13 contrast, daptomycin can be an effective treatment option via intrathecal or intraventricular

14 administration when neurosurgical access is available. [52]

15 Distribution into peritoneal fluid. After IV administration, Gika et al. reported good 16 daptomycin distribution within peritoneal fluid, although the ratio between area under the 17 curve (AUC) was not indicated.[37] Intraperitoneal administration of daptomycin has been 18 reported for peritoneal dialysis patients with peritonitis. [51, 62, 63] A $300 \mathrm{mg}$ dose allowed 19 to reach effective concentrations in dialysate, and the systemic bioavailability was high 20 (70\%). However, this should be considered with caution since peritonitis may have increase 21 peritoneal permeability and thus increase the bioavailability. [51]

22 Distribution into bone and synovial fluid. The penetration of daptomycin into bone is good, 23 with a ratio of unbound AUC of daptomycin in bone and plasma of about 1. [64] This makes 24 daptomycin an attractive antibiotic for treatment of staphylococcal prosthetic joint infection. 
1 [65] Similarly, bone penetration has been shown to be sufficient for the treatment of the

2 diabetic foot infections. [66, 67]

3 Cardiac distribution. Daptomycin is used for the treatment of infectious endocarditis due to

4 its good diffusion within the vegetations [68] as well as at the level of the cardiac valves [69].

\section{$5 \quad 9.4 \quad$ Elimination}

6 Daptomycin is primarily eliminated by the kidney. In a radiolabelled study in healthy 7 volunteers, $78 \%$ of the dose was recovered in urine, of which $52 \%$ were biologically active; 8 the rest was proposed to be peptide fragments produced during renal excretion or within 9 urinary bladder. [13, 46] Indeed, the kidney is known to be an active site of peptide 10 degradation due to the presence of peptidases, and it can be noted that in rats, high 11 concentrations of daptomycin have been found in the kidneys where it can be degraded. [70,

12 71] Based on PK results in healthy volunteers, unbound renal clearance of daptomycin can be estimated to vary between 60 and $80 \mathrm{~mL} / \mathrm{min}$, which is less than the glomerular filtration rate 14 and therefore suggests tubular reabsorption.[54] It is of note that probenecid had no effect on the PK of daptomycin, suggesting that organic anion transporters (OAT) are not involved in 16 renal elimination of daptomycin. [13] Non-renal elimination of daptomycin does not involve cytochrome P450 enzymes, and preclinical PK studies indicated that daptomycin does not appear to inhibit or induce any of

19 the key cytochrome P450 isoenzymes. [13] In healthy volunteers, after IV administration of 20 radiolabelled daptomycin $\left({ }^{14} \mathrm{C}\right.$-daptomycin), $5 \%$ of the ${ }^{14} \mathrm{C}$ dose was recovered in faeces.[46]

21 It has been shown in a clinical case that after administration of daptomycin at $8 \mathrm{mg} / \mathrm{kg} / \mathrm{day}$ the 22 concentrations of daptomycin in bile were comparable to those in plasma.[72]

\subsection{Drug-drug interactions}


1 Since daptomycin has little or no metabolism by cytochrome P450, metabolic drug-drug

2 interactions are unlikely. On the other hand, its renal elimination poses a possible risk of

3 decreased clearance when given concomitantly with drugs that reduce glomerular filtration

4 rate, such as non-steroidal anti-inflammatory drugs.[13]

5 So far, no interactions requiring precautionary measures have been reported due to its high

6 protein binding.

\section{$7 \quad 9.6 \quad$ Protein binding.}

8 In plasma, daptomycin binds reversibly and primarily to albumin with an averaged bound

9 fraction of about $90-95 \%$ in healthy volunteers. [46, 73] This high protein binding would

10 justify to measure unbound concentrations, which can be done by different methods but which

11 is complicated by the fact that daptomycin binds to the separation membranes (see bioanalysis

12 section). If measurement of free concentrations is not possible, at least the factors that may

13 alter protein binding should be considered. In that respect, it was shown that the fraction of

14 daptomycin bound to proteins in plasma depends little on the level of daptomycin

15 concentrations but increases with albuminemia. [27] A change in protein binding has

16 theoretically no effect on average free drug concentration at steady-state, but it does affect

17 average total concentration at steady-state. [74-76] Thus, while the total concentration at 18 steady-state (Css) depends on the free fraction $\left(f_{u}\right)$ and on the clearance of unbound 19 concentration $\left(\mathrm{CL}_{u}\right)$ (Eq.1), the unbound concentration at steady-state $\left(\mathrm{Css}_{\mathrm{u}}\right)$ is independent of 20 fu (Eq.2):

$$
\text { Css }=\frac{\text { Daily dose }}{\mathrm{CL}}=\frac{\text { Daily dose }}{\mathrm{f}_{\mathrm{u}} \times \mathrm{CL}_{\mathrm{u}}} \quad(\text { Eq.1) }
$$

$$
\mathrm{Css}_{\mathrm{u}}=\mathrm{f}_{\mathrm{u}} \times \mathrm{Css}=\frac{\text { Daily dose }}{\mathrm{CL}_{\mathrm{u}}}
$$


1 Thus, the area under the curve of free concentrations $\left(\mathrm{AUC}_{\mathrm{u}}\right)$, which is the parameter related

2 to the efficacy of daptomycin, is also independent of $f_{u}$ (Eq.3).

$$
\mathrm{AUC}_{\mathrm{u}}=\mathrm{Css}_{\mathrm{u}} \times \text { Dosing Interval }=\frac{\text { Daily dose } \times \text { Dosing Interval }}{\mathrm{CL}_{\mathrm{u}}}
$$

4 Since daptomycin is strongly bound a relatively small change in protein binding (eg: from $590 \%$ to $95 \%$ ) will have a much higher effect on fu (in that case from $10 \%$ to $5 \%$ ). As an 6 illustration, in a study in intensive care unit (ICU) patients with variable renal function, the $f_{u}$ varied by 8 fold between patients (from $4 \%$ to $33 \%$ ). Therefore, different values of total concentrations may correspond to the same free concentration (Eq.2). For example, in case of

9 low albuminemia (and high $\mathrm{f}_{\mathrm{u}}$ ), a low total concentration of daptomycin could lead to the 10 erroneous belief that a patient is underdosed. [27] In vitro, the presence of calcium at 11 physiological concentrations increases the binding of daptomycin to serum albumin from $85 \%$ to $96 \%$. [73] It is therefore important to control calcium concentration when performing 13 protein binding experiments with daptomycin. The clinical impact of this observation has not

14 been evaluated. Finally, it should be noted that in vitro, the effective concentration could 15 differ from the free concentration.[77] Whether this is confirmed in vivo remains to be 16 established.

\section{$17 \quad 9.7 \quad$ PK in healthy volunteers}

18 In healthy volunteers, when considering total concentrations, daptomycin has a volume of distribution of $\sim 0.1 \mathrm{~L} / \mathrm{kg}$ (7 L), a systemic clearance of $\sim 8-10 \mathrm{~mL} / \mathrm{h} / \mathrm{kg}(0.56-0.70 \mathrm{~L} / \mathrm{h}=9.3-$

$2011.7 \mathrm{~mL} / \mathrm{min}$ ), a fraction of dose excreted unchanged in urine of $\sim 54 \%$, a protein binding of $21 \sim 92 \%$, a half-life $\left(\mathrm{t}_{1 / 2}\right)$ of $\sim 8-9$ h. [53, 54] Daptomycin PK is almost linear in the 4 to $2212 \mathrm{mg} / \mathrm{kg}$ dose range, regarding AUC, peak concentration (Cmax) and Cmin levels. [53, 54, 23 78] After daptomycin administration as a bolus (10 s or $2 \mathrm{~min}$ ), the AUC and the Cmin were 
1 equivalent to those obtained after administration as a $30 \mathrm{~min}$ infusion. [78, 79] However, after

2 the bolus, the Cmax was higher than after the 30-minute infusion

\section{$3 \quad 9.8 \quad$ PK in special populations}

4 It should be noted that, due to the difficulty of measuring free concentrations, most studies in special populations have been conducted using total concentrations, making interpretation more difficult.

Renal impairment. Clearance and therefore AUC decrease while and $t_{1 / 2}$ increases with decreasing renal function. [27, 80-82] Compared with critically ill patients with normal renal function (creatinine clearance, CLcr=120 $\mathrm{mL} / \mathrm{min}$ ), urinary excretion dropped from $61 \%$ to $21 \%$ while AUC jumped by 2 -folds in critically ill patients with severe renal insufficiency

11 (CLcr=20 mL/min). [27] This illustrates that neither total clearance nor renal excretion clearance is proportional to glomerular filtration rate because elimination is only partially renal and renal impairment may alter the free fraction and tubular reabsorption. Also, $\mathrm{t}_{1 / 2}$ was

$14 \sim 19 \mathrm{~h}$ in patients with $\mathrm{CLcr} \leq 40 \mathrm{~mL} / \mathrm{min} v s \sim 8 \mathrm{~h}$ in patients with CLcr $\geq 80 \mathrm{~mL} / \mathrm{min}$. [80] In order to take into account this effect of renal impairment on daptomycin PK, it is recommended to administer daptomycin once every $48 \mathrm{~h}$ instead of once every $24 \mathrm{~h}$ for patients with CLcr lower than $30 \mathrm{~mL} / \mathrm{min}$. [48]

PK in patients with haemodialysis. PK of daptomycin in patients undergoing continuous renal replacement therapy (CRRT) have been described by several groups. [83-87] Daptomycin is excreted during CRRT, mean total clearances estimated during continuous veno-venous haemodialysis (CVVHD) varied between 0.68 and $1.03 \mathrm{~L} / \mathrm{h}$ (corresponding to 11 and $17 \mathrm{~mL} / \mathrm{min}) .[83,85,88-91]$ Mean total clearances estimated during continuous venovenous haemodiafiltration (CVVHDF) varied between 0.36 and $0.61 \mathrm{~L} / \mathrm{h} .[83,84,86,87]$

24 These values are quite close to the clearance values observed in healthy volunteers $(0.56$ - 
$10.70 \mathrm{~L} / \mathrm{h}$ ). Based on these results, the authors performed simulations to determine the most

2 appropriate dosing regimens to achieve the efficacy targets and to avoid muscle toxicity. It is

3 important to note that the unbound fraction of daptomycin was twice higher in haemodialyzed

4 critically ill patients compared with values reported in non-haemodialyzed patients (16-18\%

5 vs 9\%). [27, 85, 86] Accordingly, as simulations performed in these studies were performed

6 from total concentrations, actual unbound concentrations should have been underestimated as

7 well as PTA to reach efficacy and toxicity targets. Dosing recommendations for patients

8 undergoing CRRT are still a matter of debate. Thus, the dosages recommended by the various

9 authors range from $6 \mathrm{mg} / \mathrm{kg}$ q $48 \mathrm{~h}$ to $8 \mathrm{mg} / \mathrm{kg} \mathrm{q} 24 \mathrm{~h}$. [83-91]

10 Clearance of daptomycin in patients undergoing continuous ambulatory peritoneal dialysis

11 (CAPD) was reported to be $0.31 \mathrm{~L} / \mathrm{h}$. [92] In that case, an IV administration of daptomycin 4

12 to $6 \mathrm{mg} / \mathrm{kg}$ q48h appears to be adequate to achieve effective plasma concentrations. [92]

13 Hepatic impairment. Results from an open label, single dose study $(6 \mathrm{mg} / \mathrm{kg})$ showed that 14 moderate hepatic impairment (Child-Pugh B) did not affect daptomycin PK. [13] No data are 15 available for severe hepatic impairment, therefore daptomycin should be used with caution for 16 these patients. In addition, hepatic failure may be accompanied by hypoalbuminemia which 17 may alter protein binding of daptomycin.

Obese. Regulatory agencies approved daptomycin dosing proportional to actual body weight

19 (4 or $6 \mathrm{mg} / \mathrm{kg} / \mathrm{day}$ depending on indication). When considering non-weight-normalized parameters, the volume of distribution $[80,93,94]$ and the elimination clearance $[87,94]$ of

21 daptomycin have been shown to increase with body weight. However, after administration of 22 a weight-proportional dose of daptomycin, exposure (AUC, Cmax, Cmin) was $25 \%$ to $93 \%$ 23 higher in obese subjects compared to non-obese subjects. [94-96] Moreover, complicated 24 obese patients who received daptomycin dosed on actual body weight have increased rates of 
1 CPK elevations. [97] Thus, dosing regimens, either fixed (500 mg/day), based on ideal body

2 weight or based on adjusted body weight (calculated according to a function depending on

3 actual and ideal body weights), have been proposed. [96, 98-100] Although it appears that the

4 administration of fixed doses is most likely to lead to comparable exposures between obese

5 and non-obese patients, this approach needs to be better evaluated and the determination of

6 fixed doses to achieve effective exposure in obese patients remains to be done. [96]

7 Furthermore, in order to make dose recommendations in obese patients, it seems important to

8 measure the free fraction in this population.

9 Gender. In two studies, clearance has been shown to be $20-44 \%$ lower for female subjects than for male subjects. [56, 80, 81] However, in some other studies, difference of clearance between genders was not significant. $[82,101]$ It may be hypothesized that gender could be a better descriptor of the influence of body size on the clearance of daptomycin, but this 13 requires further investigation.[56].

Paediatrics. After single administration of daptomycin $4 \mathrm{mg} / \mathrm{kg}$, daptomycin clearance was about $20 \mathrm{~mL} / \mathrm{h} / \mathrm{kg}$ in children younger than 6 years and in young infants $<12$ months (compared to $8-10 \mathrm{~mL} / \mathrm{h} / \mathrm{kg}$ in healthy volunteers).[102-104] The systemic exposure in paediatric patients younger than 6 years was lower than in adolescents (12-17 years, CL 11 $\mathrm{mL} / \mathrm{h} / \mathrm{kg})$ and adults $(\mathrm{CL} \sim 8.3 \mathrm{~mL} / \mathrm{h} / \mathrm{kg}$ ) for the same dose, due to decreased clearance with age. $[48,102]$ This results in under-exposure in children [102-104] and higher weight-based (i.e. $\mathrm{mg} / \mathrm{kg}$ ) doses of daptomycin may be required to achieve the efficacious exposures observed in adults. [105, 106] A single 8 or $10 \mathrm{mg} / \mathrm{kg}$ dose for children aged 2 to 6 years led to exposures comparable to those obtained in adults for a $4-6 \mathrm{mg} / \mathrm{kg}$ dose. [48, 107] Moreover, a report of two infants $<2$ months receiving $6 \mathrm{mg} / \mathrm{kg}$ daptomycin every $12 \mathrm{~h}$ 24 concluded that this dosage was equivalent to adults treated with $4 \mathrm{mg} / \mathrm{kg}$ every $24 \mathrm{~h}$. [108] 25 Antachopoulos et al. even proposed that doses higher than $6 \mathrm{mg} / \mathrm{kg} / 12 \mathrm{~h}$ should be used.[109] 
1 However, it is known that protein binding of drugs may be decreased in children, and should

2 therefore be evaluated for daptomycin in order to correctly interpret these results obtained for

3 total concentrations. [110]

4 Elderly. An open-label, single-dose (4 mg/kg) Phase I study showed that total exposure $5 \quad\left(\mathrm{AUC}_{0-\infty}\right)$ of daptomycin was $58 \%$ higher in geriatric subjects 75 years old compared with 6 younger subjects between 18 and 30 years old.[111] The 35\% lower clearance explaining this

7 difference in exposure was in fact not due to the difference in age but to the difference in 8 renal function. No statistical differences in Cmax and volume of distribution were observed 9 between geriatric and younger subjects.

$P K$ in critically ill patients. Intensive care unit (ICU) patients with infections often have other co-morbidities, such as renal failure, hypoalbuminemia, or obesity. In addition, the presence of sepsis may lead to acute renal failure and require haemodialysis. Therefore, they are at risk of having altered pharmacokinetics of daptomycin. As a matter of fact, pharmacokinetics of 14 daptomycin is highly variable between ICU patients, but also highly variable for the same patient over time. [27, 30] Compared to healthy volunteers, one of the main differences observed in ICU patients is an increase by two folds on average of the volume of distribution, on average about twice as much $(0.2 \mathrm{~L} / \mathrm{kg}$ vs $0.1 \mathrm{~L} / \mathrm{kg})$. [25, 27, 30, 112] Reported clearances values are dependent on the renal function of patients included in the various clinical trials. $[25,27,30,112]$ In order to reach PK/PD targets for efficacy, it is generally recommended to give high, and off-label, doses of daptomycin $(10 \mathrm{mg} / \mathrm{kg} / \mathrm{day}$ or $560-840 \mathrm{mg} / \mathrm{day})$ to ICU 21 patients, except for those with reduced renal function, and to perform therapeutic drug monitoring. [25, 27, 30, 112] The pathophysiological state of ICU patients is rarely stable over time and this can affect the PK of daptomycin. For example, augmented renal clearance or the presence of sepsis may induce a decrease in daptomycin concentrations. [25, 113] The fact that the septic state of patients tends to improve over time has led some authors to 
1 propose that the dosage of daptomycin should be adapted to the evolution of the pathology, in

2 particular with high doses during the first days $(10 \mathrm{mg} / \mathrm{kg} /$ day or $750 \mathrm{mg} /$ day $)$ then lower

3 doses. [113] Overall, the unstable nature of the PK of daptomycin in ICU patients seems to be

4 a strong argument for clinicians to use therapeutic drug monitoring for this patient population.

\section{$5 \quad 10$ Therapeutic drug monitoring (TDM)}

6 TDM of daptomycin is currently not widespread, but it could benefit some patients.[114, 115]

7 Thus, some patients are at risk of having disturbed pharmacokinetics, such as ICU patients

8 with sepsis, patients with renal or hepatic insufficiency, patients with augmented renal

9 clearance, patients undergoing renal replacement therapy, obese patients, paediatric or

10 geriatric patients, or patients with severe burns. In addition, in order to monitor the risk of

11 toxicity, there is an interest in monitoring daptomycin concentrations for patients receiving

12 high doses. [116]

13 Few (one to our knowledge) commercial kits are available for the determination of 14 daptomycin, but HPLC-UV and LC-MS/MS assay methods have been published (see

15 bioanalytical section). Some targets for efficacy and toxicity have been published. A target of 16 AUC/MIC>666 may be selected for clinical efficacy, even if this value needs to be confirmed 17 in larger patient cohorts. [30] In addition, protein binding, and thus possible 18 hypoalbuminemia, should be taken into account when interpreting and comparing daptomycin assay results with this target value ( $c f$ protein binding section). A Cmin greater than $3.2 \mathrm{mg} / \mathrm{L}$ was also proposed as an efficacy target.[31] The target value for Cmin not to be exceeded in

21 order to limit the risk of undesirable muscular effects is $24.3 \mathrm{mg} / \mathrm{L}$. [2, 3, 34, 35] difficult at the moment. It is therefore based on total concentrations. Monitoring for muscle toxicity is fairly simple, since it is sufficient to measure Cmin just before next administration. 
1 On the other hand, monitoring of efficacy and estimation of AUC is more problematic and

2 requires either the use of Bayesian approaches, or the use of simplified equations requiring

3 measurements of one concentration approximately two hours after the start of the infusion and

4 of Cmin. [117] As alternative approaches, some authors have proposed that Cmin should

5 exceed $3.2 \mathrm{mg} / \mathrm{L} \mathrm{[31]} \mathrm{or} \mathrm{that} \mathrm{Cmax} \mathrm{at} \mathrm{the} \mathrm{end} \mathrm{of} \mathrm{the} \mathrm{infusion} \mathrm{should} \mathrm{exceed} 100 \mathrm{mg} / \mathrm{L}$. [85, $6 \quad 118]$

\section{Conclusion}

8 Due to a low level of resistance, daptomycin has an important place in the treatment of Gram-

9 positive infections. Its pharmacokinetics is characterized by predominantly renal elimination

10 and high protein binding ( $90 \%)$. Due to high inter-individual variability, therapeutic

11 monitoring of daptomycin concentrations may be of interest for certain patients such as ICU

12 patients, patients with renal or hepatic insufficiency, dialysis patients, obese patients or 13 children.

14 
3 Funding. No support was received for the preparation of this manuscript.

4 Conflicts of interest. Nicolas Grégoire, Alexia Chauzy, Sandrine Marchand and William

5 Couet declare that they have no conflicts of interest.

\section{References}

7 1. Eliopoulos GM, Willey S, Reiszner E, Spitzer PG, Caputo G, Moellering RC, Jr. In 8 vitro and in vivo activity of LY 146032, a new cyclic lipopeptide antibiotic. Antimicrob 9 Agents Chemother. 1986 Oct;30(4):532-5.

10 2. Tally FP, Zeckel M, Wasilewski MM, Carini C, Berman CL, Drusano GL, et al. 11 Daptomycin: a novel agent for Gram-positive infections. Expert Opin Investig Drugs. 1999 12 Aug;8(8):1223-38.

13 3. Tally FP, DeBruin MF. Development of daptomycin for gram-positive infections. J 14 Antimicrob Chemother. 2000 Oct;46(4):523-6.

15 4. Debono M, Abbott BJ, Molloy RM, Fukuda DS, Hunt AH, Daupert VM, et al. 16 Enzymatic and chemical modifications of lipopeptide antibiotic A21978C: the synthesis and 17 evaluation of daptomycin (LY146032). The Journal of antibiotics. 1988 Aug;41(8):1093-105.

18 5. Totoli EG, Garg S, Salgado HR. Daptomycin: Physicochemical, Analytical, and 19 Pharmacological Properties. Therapeutic drug monitoring. 2015 Dec;37(6):699-710.

20 6. Qiu J, Yu L, Kirsch LE. Estimated pKa values for specific amino acid residues in 21 daptomycin. J Pharm Sci. 2011 Oct;100(10):4225-33.

22 7. Zupancic O, Partenhauser A, Lam HT, Rohrer J, Bernkop-Schnurch A. Development 23 and in vitro characterisation of an oral self-emulsifying delivery system for daptomycin. Eur J 24 Pharm Sci. 2016 Jan 1;81:129-36.

25 8. DrugBank. Daptomycin. [cited 2020 April 28th]; Available from: http://www.eucast.org/

9. Gray DA, Wenzel M. More Than a Pore: A Current Perspective on the In Vivo Mode of Action of the Lipopeptide Antibiotic Daptomycin. Antibiotics (Basel, Switzerland). 2020 Jan $3 ; 9(1)$.

10. Scott WR, Baek SB, Jung D, Hancock RE, Straus SK. NMR structural studies of the antibiotic lipopeptide daptomycin in DHPC micelles. Biochimica et biophysica acta. 2007 Dec;1768(12):3116-26.

11. Silverman JA, Perlmutter NG, Shapiro HM. Correlation of daptomycin bactericidal activity and membrane depolarization in Staphylococcus aureus. Antimicrob Agents Chemother. 2003 Aug;47(8):2538-44.

36 12. Kelesidis T. The Interplay between Daptomycin and the Immune System. Frontiers in 37 immunology. 2014;5:52.

38 13. European Medicines Agency. Cubicin: Scientific discussion. 2006 [cited 2020 June 39 10th]; Available from: https://www.ema.europa.eu/en/documents/scientific40 discussion/cubicin-epar-scientific-discussion_en.pdf 
14. Gonzalez-Ruiz A, Seaton RA, Hamed K. Daptomycin: an evidence-based review of its role in the treatment of Gram-positive infections. Infection and drug resistance. 2016;9:47-58. 15. Stefani S, Campanile F, Santagati M, Mezzatesta ML, Cafiso V, Pacini G. Insights and clinical perspectives of daptomycin resistance in Staphylococcus aureus: A review of the available evidence. Int J Antimicrob Agents. 2015 Sep;46(3):278-89.

16. Gomez Casanova N, Siller Ruiz M, Munoz Bellido JL. Mechanisms of resistance to daptomycin in Staphylococcus aureus. Revista espanola de quimioterapia : publicacion oficial de la Sociedad Espanola de Quimioterapia. 2017 Dec;30(6):391-6.

9 17. Tran TT, Munita JM, Arias CA. Mechanisms of drug resistance: daptomycin

18. Dortet L, Anguel N, Fortineau N, Richard C, Nordmann P. In vivo acquired daptomycin resistance during treatment of methicillin-resistant Staphylococcus aureus endocarditis. International journal of infectious diseases : IJID : official publication of the International Society for Infectious Diseases. 2013 Nov;17(11):e1076-7.

19. van Hal SJ, Paterson DL, Gosbell IB. Emergence of daptomycin resistance following vancomycin-unresponsive Staphylococcus aureus bacteraemia in a daptomycin-naïve patient-a review of the literature. Eur J Clin Microbiol Infect Dis. 2011 May;30(5):603-10.

20. Julian K, Kosowska-Shick K, Whitener C, Roos M, Labischinski H, Rubio A, et al. Characterization of a daptomycin-nonsusceptible vancomycin-intermediate Staphylococcus aureus strain in a patient with endocarditis. Antimicrob Agents Chemother. 2007 Sep;51(9):3445-8.

21. Cui L, Tominaga E, Neoh HM, Hiramatsu K. Correlation between Reduced Daptomycin Susceptibility and Vancomycin Resistance in Vancomycin-Intermediate Staphylococcus aureus. Antimicrob Agents Chemother. 2006 Mar;50(3):1079-82.

22. Heidary M, Khosravi AD, Khoshnood S, Nasiri MJ, Soleimani S, Goudarzi M. Daptomycin. J Antimicrob Chemother. 2018 Jan 1;73(1):1-11.

23. Louie A, Kaw P, Liu W, Jumbe N, Miller MH, Drusano GL. Pharmacodynamics of daptomycin in a murine thigh model of Staphylococcus aureus infection. Antimicrob Agents Chemother. 2001 Mar;45(3):845-51.

24. Safdar N, Andes D, Craig WA. In vivo pharmacodynamic activity of daptomycin. Antimicrob Agents Chemother. 2004 Jan;48(1):63-8.

25. Falcone M, Russo A, Venditti M, Novelli A, Pai MP. Considerations for higher doses of daptomycin in critically ill patients with methicillin-resistant Staphylococcus aureus bacteremia. Clin Infect Dis. 2013 Dec;57(11):1568-76.

26. EUCAST. Daptomycin: Rational for the EUCAST clinical breakpoints, version 1.0.13 September 2005. [cited 2020 June 9th]; Available from: https://eucast.org/fileadmin/src/media/PDFs/EUCAST_files/Rationale_documents/Daptomyci $\underline{\text { nrationale1.0.pdf }}$

27. Gregoire N, Marchand S, Ferrandiere M, Lasocki S, Seguin P, Vourc'h M, et al. Population pharmacokinetics of daptomycin in critically ill patients with various degrees of renal impairment. J Antimicrob Chemother. 2018 Oct 8.

28. Takesue Y, Mikamo H, Kusachi S, Watanabe S, Takahashi K, Yoshinari T, et al. Correlation between pharmacokinetic/pharmacodynamic indices and clinical outcomes in Japanese patients with skin and soft tissue infections treated with daptomycin: analysis of a phase III study. Diagn Microbiol Infect Dis. 2015 Sep;83(1):77-81.

29. Bhavnani SM, Ambrose PG, Hammel JP, Rubino CM, Drusano GL. Evaluation of Daptomycin Exposure and Efficacy and Safety Endpoints To Support Risk-versus-Benefit Considerations. Antimicrob Agents Chemother. 2015;60(3):1600-7.

30. Falcone M, Russo A, Cassetta MI, Lappa A, Tritapepe L, d'Ettorre G, et al. Variability of pharmacokinetic parameters in patients receiving different dosages of daptomycin: is 
therapeutic drug monitoring necessary? Journal of infection and chemotherapy : official journal of the Japan Society of Chemotherapy. 2013 Aug;19(4):732-9.

31. Galar A, Muñoz P, Valerio M, Cercenado E, García-González X, Burillo A, et al. Current use of daptomycin and systematic therapeutic drug monitoring: Clinical experience in a tertiary care institution. Int J Antimicrob Agents. 2019 Jan;53(1):40-8.

32. EUCAST. Breakpoint tables for interpretation of MICs and zone diameters. 2020 [cited 2020 June 11th]; Available from: https://www.eucast.org/fileadmin/src/media/PDFs/EUCAST_files/Breakpoint_tables/v_10.0 Breakpoint_Tables.pdf Pharmacodynami, Kuti JL, Weisser M, Egli A, Rybak MJ, Zasowski EJ, et al. Pharmacodynamic Analysis of Daptomycin-treated Enterococcal Bacteremia: It Is Time to Change the Breakpoint. Clin Infect Dis. 2019 May 2;68(10):1650-7.

34. Bhavnani SM, Rubino CM, Ambrose PG, Drusano GL. Daptomycin exposure and the probability of elevations in the creatine phosphokinase level: data from a randomized trial of patients with bacteremia and endocarditis. Clin Infect Dis. 2010 Jun 15;50(12):1568-74.

35. Oleson FB, Jr., Berman CL, Kirkpatrick JB, Regan KS, Lai JJ, Tally FP. Once-daily dosing in dogs optimizes daptomycin safety. Antimicrob Agents Chemother. 2000 Nov;44(11):2948-53.

36. Ando M, Nishioka H, Nakasako S, Kuramoto E, Ikemura M, Kamei H, et al. Observational retrospective single-centre study in Japan to assess the clinical significance of serum daptomycin levels in creatinine phosphokinase elevation. Journal of clinical pharmacy and therapeutics. 2020 Apr;45(2):290-7.

37. Gika HG, Michopoulos F, Divanis D, Metalidis S, Nikolaidis P, Theodoridis GA. Daptomycin determination by liquid chromatography-mass spectrometry in peritoneal fluid, blood plasma, and urine of clinical patients receiving peritoneal dialysis treatment. Analytical and bioanalytical chemistry. 2010 Jul;397(6):2191-7.

38. Naito T, Yamada T, Yagi T, Kawakami J. Simple and validated UHPLC method coupled to UV detection for determination of daptomycin in human plasma and urine. Biomedical chromatography : BMC. 2014 Mar;28(3):317-9.

39. Verdier MC, Bentue-Ferrer D, Tribut O, Collet N, Revest M, Bellissant E. Determination of daptomycin in human plasma by liquid chromatography-tandem mass spectrometry. Clinical application. Clinical chemistry and laboratory medicine. 2011 Jan;49(1):69-75.

40. Baietto L, D'Avolio A, Pace S, Simiele M, Marra C, Ariaudo A, et al. Development and validation of an UPLC-PDA method to quantify daptomycin in human plasma and in dried plasma spots. J Pharm Biomed Anal. 2014 Jan;88:66-70.

41. Luci G, Cucchiara F, Ciofi L, Lastella M, Danesi R, Di Paolo A. A new validated HPLC-UV method for therapeutic monitoring of daptomycin in comparison with reference mass spectrometry. J Pharm Biomed Anal. 2020 Apr 15;182:113132.

42. Tobin CM, Darville JM, Lovering AM, Macgowan AP. An HPLC assay for daptomycin in serum. J Antimicrob Chemother. 2008 Dec;62(6):1462-3.

43. Szultka M, Krzeminski R, Jackowski M, Buszewski B. Simultaneous determination of selected chemotherapeutics in human whole blood by molecularly imprinted polymers coated solid phase microextraction fibers and liquid chromatography-tandem mass spectrometry. Journal of chromatography B, Analytical technologies in the biomedical and life sciences. 2013 Dec 1;940:66-76.

44. Barco S, Mesini A, Barbagallo L, Maffia A, Tripodi G, Pea F, et al. A liquid chromatography-tandem mass spectrometry platform for the routine therapeutic drug monitoring of 14 antibiotics: Application to critically ill pediatric patients. J Pharm Biomed Anal. 2020 Jul 15;186:113273. 
45. Ogami C, Tsuji Y, Kasai H, Hiraki Y, Yamamoto Y, Matsunaga K, et al. Evaluation of pharmacokinetics and the stability of daptomycin in serum at various temperatures. International journal of infectious diseases : IJID : official publication of the International Society for Infectious Diseases. 2017 Apr;57:38-43.

46. Woodworth JR, Nyhart EH, Jr., Brier GL, Wolny JD, Black HR. Single-dose pharmacokinetics and antibacterial activity of daptomycin, a new lipopeptide antibiotic, in healthy volunteers. Antimicrob Agents Chemother. 1992 Feb;36(2):318-25.

8 47. Kim A, Suecof LA, Sutherland CA, Gao L, Kuti JL, Nicolau DP. In vivo microdialysis 9 study of the penetration of daptomycin into soft tissues in diabetic versus healthy volunteers.

48. European Medicines Agency. Cubicin: Summary of product characteristics. 2010 [cited 2020 June 10th]; Available from: https://www.ema.europa.eu/en/documents/productinformation/cubicin-epar-product-information_en.pdf

49. Purandare A. Clinical Review NDA 021572. Cubicin (daptomycin for injection). . 2017 Accessed on 2020-06-25 [cited; Available from: https://www.fda.gov/downloads/Drugs/DevelopmentApprovalProcess/DevelopmentResource s/UCM552588.pdf

50. Rister N. Clinical Review NDA 021572. Cubicin (daptomycin for injection). . 2017 Accessed on 2020-06-25 [cited; Available from: https://www.fda.gov/media/108529/download

51. Saint Paul LP, Ficheux M, Debruyne D, Loilier M, Bouvier N, Morello R, et al. Pharmacokinetics of $300 \mathrm{mg} / \mathrm{d}$ Intraperitoneal Daptomycin: New Insight from the DaptoDP Study. Peritoneal dialysis international : journal of the International Society for Peritoneal Dialysis. 2018 Nov-Dec;38(6):463-6.

52. Lee BJ, Vu BN, Seddon AN, Hodgson HA, Wang SK. Treatment Considerations for CNS Infections Caused by Vancomycin-Resistant Enterococcus faecium: A Focused Review of Linezolid and Daptomycin. The Annals of pharmacotherapy. 2020 Jun 8:1060028020932513.

53. Benvenuto M, Benziger DP, Yankelev S, Vigliani G. Pharmacokinetics and tolerability of daptomycin at doses up to 12 milligrams per kilogram of body weight once daily in healthy volunteers. Antimicrob Agents Chemother. 2006 Oct;50(10):3245-9.

54. Dvorchik BH, Brazier D, DeBruin MF, Arbeit RD. Daptomycin pharmacokinetics and safety following administration of escalating doses once daily to healthy subjects. Antimicrob Agents Chemother. 2003 Apr;47(4):1318-23.

55. Lemaire S, Van Bambeke F, Mingeot-Leclercq MP, Tulkens PM. Modulation of the cellular accumulation and intracellular activity of daptomycin towards phagocytized Staphylococcus aureus by the P-glycoprotein (MDR1) efflux transporter in human THP-1 macrophages and madin-darby canine kidney cells. Antimicrob Agents Chemother. 2007 Aug;51(8):2748-57.

56. Bricca R, Goutelle S, Roux S, Gagnieu MC, Becker A, Conrad A, et al. Genetic polymorphisms of ABCB1 (P-glycoprotein) as a covariate influencing daptomycin pharmacokinetics: a population analysis in patients with bone and joint infection. $J$ Antimicrob Chemother. 2019 Apr 1;74(4):1012-20.

57. Benefield RJ, Slechta ES, Gast CM, Spivak ES, Hanson KE, Alexander DP. Comparison of the Drug-Drug Interaction Potential of Daptomycin in Combination with Rifampin in Healthy Adult Volunteers. Antimicrob Agents Chemother. 2018 Dec;62(12).

58. Van der Auwera P, Matsumoto T, Husson M. Intraphagocytic penetration of antibiotics. J Antimicrob Chemother. 1988 Aug;22(2):185-92.

59. Lehar SM, Pillow T, Xu M, Staben L, Kajihara KK, Vandlen R, et al. Novel antibodyantibiotic conjugate eliminates intracellular S. aureus. Nature. 2015 Nov 19;527(7578):323-8. 
60. Taylor SD, Palmer M. The action mechanism of daptomycin. Bioorganic \& medicinal chemistry. 2016 Dec 15;24(24):6253-68.

61. Piva S, Di Paolo A, Galeotti L, Ceccherini F, Cordoni F, Signorini L, et al. Daptomycin Plasma and CSF Levels in Patients with Healthcare-Associated Meningitis. Neurocritical care. 2019 Aug;31(1):116-24.

6 62. Bahte SK, Bertram A, Burkhardt O, Martens-Lobenhoffer J, Goedecke V, Bode-Boger $7 \mathrm{SM}$, et al. Therapeutic serum concentrations of daptomycin after intraperitoneal 8 administration in a patient with peritoneal dialysis-associated peritonitis. J Antimicrob 9 Chemother. 2010 Jun;65(6):1312-4. Pharmacokinetics of Intraperitoneal Daptomycin in Patients with Peritoneal Dialysis-Related Peritonitis. Peritoneal dialysis international : journal of the International Society for Peritoneal Dialysis. 2017 Jan 2;37(1):44-50.

64. Montange D, Berthier F, Leclerc G, Serre A, Jeunet L, Berard M, et al. Penetration of daptomycin into bone and synovial fluid in joint replacement. Antimicrob Agents Chemother. 2014 Jul;58(7):3991-6.

65. Carli AV, Miller AO, Kapadia M, Chiu YF, Westrich GH, Brause BD, et al. Assessing the Role of Daptomycin as Antibiotic Therapy for Staphylococcal Prosthetic Joint Infection. Journal of bone and joint infection. 2020;5(2):82-8.

66. Grillon A, Argemi X, Gaudias J, Ronde-Ousteau C, Boeri C, Jenny JY, et al. Bone penetration of daptomycin in diabetic patients with bacterial foot infections. International journal of infectious diseases : IJID : official publication of the International Society for Infectious Diseases. 2019 Aug;85:127-31.

67. Traunmüller F, Schintler MV, Metzler J, Spendel S, Mauric O, Popovic M, et al. Soft tissue and bone penetration abilities of daptomycin in diabetic patients with bacterial foot infections. J Antimicrob Chemother. 2010 Jun;65(6):1252-7.

68. Caron F, Kitzis MD, Gutmann L, Cremieux AC, Maziere B, Vallois JM, et al. Daptomycin or teicoplanin in combination with gentamicin for treatment of experimental endocarditis due to a highly glycopeptide-resistant isolate of Enterococcus faecium. Antimicrob Agents Chemother. 1992 Dec;36(12):2611-6.

69. Tascini C, Di Paolo A, Poletti R, Flammini S, Emdin M, Ciullo I, et al. Daptomycin concentrations in valve tissue and vegetation in patients with bacterial endocarditis. Antimicrob Agents Chemother. 2013 Jan;57(1):601-2.

70. Kreft B, de Wit C, Krech R, Marre R, Schulz E, Sack K. Experimental studies on nephrotoxicity and pharmacokinetics of LY 146032 (daptomycin) in rats. J Antimicrob Chemother. 1990 Apr;25(4):635-43.

71. Diao L, Meibohm B. Pharmacokinetics and pharmacokinetic-pharmacodynamic correlations of therapeutic peptides. Clin Pharmacokinet. 2013 Oct;52(10):855-68.

72. Tascini C, Di Paolo A, Polillo M, Ferrari M, Lambelet P, Danesi R, et al. Case report of a successful treatment of methicillin-resistant Staphylococcus aureus (MRSA) bacteremia and MRSA/vancomycin-resistant Enterococcus faecium cholecystitis by daptomycin. Antimicrob Agents Chemother. 2011 May;55(5):2458-9.

73. Schneider EK, Huang JX, Carbone V, Han M, Zhu Y, Nang S, et al. Plasma Protein Binding Structure-Activity Relationships Related to the N-Terminus of Daptomycin. ACS infectious diseases. 2017 Mar 10;3(3):249-58.

74. Zeitlinger MA, Derendorf H, Mouton JW, Cars O, Craig WA, Andes D, et al. Protein binding: do we ever learn? Antimicrob Agents Chemother. 2011 Jul;55(7):3067-74.

75. Benet LZ, Hoener BA. Changes in plasma protein binding have little clinical relevance. Clin Pharmacol Ther. 2002 Mar;71(3):115-21. 
76. Toutain PL, Bousquet-Melou A. Free drug fraction vs free drug concentration: a matter of frequent confusion. Journal of veterinary pharmacology and therapeutics. 2002 Dec;25(6):460-3.

77. Garonzik SM, Lenhard JR, Forrest A, Holden PN, Bulitta JB, Tsuji BT. Defining the Active Fraction of Daptomycin against Methicillin-Resistant Staphylococcus aureus (MRSA) Using a Pharmacokinetic and Pharmacodynamic Approach. PLoS One. 2016;11(6):e0156131. 78. Chakraborty A, Roy S, Loeffler J, Chaves RL. Comparison of the pharmacokinetics, safety and tolerability of daptomycin in healthy adult volunteers following intravenous administration by $30 \mathrm{~min}$ infusion or $2 \mathrm{~min}$ injection. J Antimicrob Chemother. 2009 Jul;64(1):151-8.

79. Aoki I, Ishikawa K, Wakana A, Aso M, Yoshinari T. Evaluation of the safety, tolerability, and pharmacokinetics of a single bolus injection of daptomycin in healthy Japanese subjects. Journal of infection and chemotherapy : official journal of the Japan Society of Chemotherapy. 2015 Mar;21(3):170-5.

80. Dvorchik B, Arbeit RD, Chung J, Liu S, Knebel W, Kastrissios H. Population pharmacokinetics of daptomycin. Antimicrob Agents Chemother. 2004 Aug;48(8):2799-807.

81. Goutelle S, Roux S, Gagnieu MC, Valour F, Lustig S, Ader F, et al. Pharmacokinetic Variability of Daptomycin during Prolonged Therapy for Bone and Joint Infections. Antimicrob Agents Chemother. 2016 May;60(5):3148-51.

82. Di Paolo A, Tascini C, Polillo M, Gemignani G, Nielsen EI, Bocci G, et al. Population pharmacokinetics of daptomycin in patients affected by severe Gram-positive infections. Int J Antimicrob Agents. 2013 Sep;42(3):250-5.

83. Xu X, Khadzhynov D, Peters H, Chaves RL, Hamed K, Levi M, et al. Population pharmacokinetics of daptomycin in adult patients undergoing continuous renal replacement therapy. Br J Clin Pharmacol. 2017 Mar;83(3):498-509.

84. Corti N, Rudiger A, Chiesa A, Marti I, Jetter A, Rentsch K, et al. Pharmacokinetics of daily daptomycin in critically ill patients undergoing continuous renal replacement therapy. Chemotherapy. 2013;59(2):143-51.

85. Vilay AM, Grio M, Depestel DD, Sowinski KM, Gao L, Heung M, et al. Daptomycin pharmacokinetics in critically ill patients receiving continuous venovenous hemodialysis. Critical care medicine. 2011 Jan;39(1):19-25.

86. Wenisch JM, Meyer B, Fuhrmann V, Saria K, Zuba C, Dittrich P, et al. Multiple-dose pharmacokinetics of daptomycin during continuous venovenous haemodiafiltration. J Antimicrob Chemother. 2012 Apr;67(4):977-83.

87. Xie F, Li S, Cheng Z. Population pharmacokinetics and dosing considerations of daptomycin in critically ill patients undergoing continuous renal replacement therapy. J Antimicrob Chemother. 2020 Feb 21.

88. Burkhardt O, Joukhadar C, Traunmuller F, Hadem J, Welte T, Kielstein JT. Elimination of daptomycin in a patient with acute renal failure undergoing extended daily dialysis. J Antimicrob Chemother. 2008 Jan;61(1):224-5.

89. Kielstein JT, Eugbers C, Bode-Boeger SM, Martens-Lobenhoffer J, Haller H, Joukhadar C, et al. Dosing of daptomycin in intensive care unit patients with acute kidney injury undergoing extended dialysis--a pharmacokinetic study. Nephrology, dialysis, transplantation : official publication of the European Dialysis and Transplant Association European Renal Association. 2010 May;25(5):1537-41. 90. Falcone M, Russo A, Cassetta MI, Lappa A, Tritapepe L, Fallani S, et al. Daptomycin serum levels in critical patients undergoing continuous renal replacement. Journal of chemotherapy (Florence, Italy). 2012 Oct;24(5):253-6.

91. Khadzhynov D, Slowinski T, Lieker I, Spies C, Puhlmann B, König T, et al. Plasma pharmacokinetics of daptomycin in critically ill patients with renal failure and undergoing 
CVVHD. International journal of clinical pharmacology and therapeutics. 2011 Nov;49(11):656-65.

92. Cardone KE, Lodise TP, Patel N, Hoy CD, Meola S, Manley HJ, et al. Pharmacokinetics and pharmacodynamics of intravenous daptomycin during continuous ambulatory peritoneal dialysis. Clinical journal of the American Society of Nephrology : CJASN. 2011 May;6(5):1081-8.

93. Cojutti PG, Candoni A, Ramos-Martin V, Lazzarotto D, Zannier ME, Fanin R, et al. Population pharmacokinetics and dosing considerations for the use of daptomycin in adult patients with haematological malignancies. J Antimicrob Chemother. 2017 Aug 1;72(8):234250 .

94. Dvorchik BH, Damphousse D. The pharmacokinetics of daptomycin in moderately obese, morbidly obese, and matched nonobese subjects. J Clin Pharmacol. 2005 Jan;45(1):4856.

95. Pai MP, Norenberg JP, Anderson T, Goade DW, Rodvold KA, Telepak RA, et al. Influence of morbid obesity on the single-dose pharmacokinetics of daptomycin. Antimicrob Agents Chemother. 2007 Aug;51(8):2741-7.

96. Butterfield-Cowper JM, Lodise TP, Jr., Pai MP. A Fixed versus Weight-Based Dosing Strategy of Daptomycin May Improve Safety in Obese Adults. Pharmacotherapy. 2018 Sep;38(9):981-5.

97. Bookstaver PB, Bland CM, Qureshi ZP, Faulkner-Fennell CM, Sheldon MA, Caulder $\mathrm{CR}$, et al. Safety and effectiveness of daptomycin across a hospitalized obese population: results of a multicenter investigation in the southeastern United States. Pharmacotherapy. 2013 Dec;33(12):1322-30.

98. Fox AN, Smith WJ, Kupiec KE, Harding SJ, Resman-Targoff BH, Neely SB, et al. Daptomycin dosing in obese patients: analysis of the use of adjusted body weight versus actual body weight. Therapeutic advances in infectious disease. 2019 JanDec;6:2049936118820230.

99. Lorenzo MP, Housman EL, Housman ST. Evaluation of Fixed-Dose Daptomycin in Obese Patients With Bloodstream Infections Caused by Staphylococcus aureus. The Annals of pharmacotherapy. 2020 Mar;54(3):290-1.

100. Ng JK, Schulz LT, Rose WE, Fox BC, Andes DR, Buhr KA, et al. Daptomycin dosing based on ideal body weight versus actual body weight: comparison of clinical outcomes. Antimicrob Agents Chemother. 2014;58(1):88-93.

101. Soraluce A, Asin-Prieto E, Rodriguez-Gascon A, Barrasa H, Maynar J, Carcelero E, et al. Population pharmacokinetics of daptomycin in critically ill patients. Int $\mathbf{J}$ Antimicrob Agents. 2018 Aug;52(2):158-65.

102. Abdel-Rahman SM, Benziger DP, Jacobs RF, Jafri HS, Hong EF, Kearns GL. Singledose pharmacokinetics of daptomycin in children with suspected or proved gram-positive infections. The Pediatric infectious disease journal. 2008 Apr;27(4):330-4.

103. Bradley JS, Benziger D, Bokesch P, Jacobs R. Single-dose pharmacokinetics of daptomycin in pediatric patients 3-24 months of age. The Pediatric infectious disease journal. 2014 Sep;33(9):936-9.

104. Cohen-Wolkowiez M, Watt KM, Hornik CP, Benjamin DK, Jr., Smith PB. Pharmacokinetics and tolerability of single-dose daptomycin in young infants. The Pediatric infectious disease journal. 2012 Sep;31(9):935-7.

105. Wei XC, Zhao MF, Li X, Xiao X. Pharmacokinetic/Pharmacodynamic Analysis of Daptomycin Against Staphylococcus aureus and Enterococcus faecium in Pediatric Patients by Monte Carlo Simulation. J Clin Pharmacol. 2020 Jun;60(6):768-74.

106. Arrieta AC, Bradley JS, Popejoy MW, Bensaci M, Grandhi A, Bokesch P, et al. Randomized Multicenter Study Comparing Safety and Efficacy of Daptomycin Versus 
Standard-of-care in Pediatric Patients With Staphylococcal Bacteremia. The Pediatric infectious disease journal. 2018 Sep;37(9):893-900.

107. Abdel-Rahman SM, Chandorkar G, Akins RL, Bradley JS, Jacobs RF, Donovan J, et al. Single-dose pharmacokinetics and tolerability of daptomycin 8 to $10 \mathrm{mg} / \mathrm{kg}$ in children aged 2 to 6 years with suspected or proved Gram-positive infections. The Pediatric infectious disease journal. 2011 Aug;30(8):712-4.

108. Cohen-Wolkowiez M, Smith PB, Benjamin DK, Jr., Fowler VG, Jr., Wade KC. Daptomycin use in infants: report of two cases with peak and trough drug concentrations.

9 Journal of perinatology : official journal of the California Perinatal Association. 2008 Mar;28(3):233-4.

109. Antachopoulos C, Iosifidis E, Sarafidis K, Bazoti F, Gikas E, Katragkou A, et al. Serum levels of daptomycin in pediatric patients. Infection. 2012 Aug;40(4):367-71.

110. Principi N, Caironi M, Venturini F, Pani L, Esposito S. Daptomycin in paediatrics: current knowledge and the need for future research. J Antimicrob Chemother. 2015 Mar;70(3):643-8.

111. Dvorchik B, Damphousse D. Single-dose pharmacokinetics of daptomycin in young and geriatric volunteers. J Clin Pharmacol. 2004 Jun;44(6):612-20.

112. Soraluce A, Asín-Prieto E, Rodríguez-Gascón A, Barrasa H, Maynar J, Carcelero E, et al. Population pharmacokinetics of daptomycin in critically ill patients. Int $\mathrm{J}$ Antimicrob Agents. 2018 Aug;52(2):158-65.

113. Di Paolo A, Polillo M, Tascini C, Lewis R, Menichetti F, Danesi R. Different recommendations for daptomycin dosing over time in patients with severe infections. Clin Infect Dis. 2014 Jun;58(12):1788-9.

114. Pea F, Cojutti P, Sbrojavacca R, Cadeo B, Cristini F, Bulfoni A, et al. TDM-guided therapy with daptomycin and meropenem in a morbidly obese, critically ill patient. The Annals of pharmacotherapy. $2011 \mathrm{Jul} ; 45(7-8): \mathrm{e} 37$.

115. Tsukada H, Tsuji Y, Yamashina T, Tsuruta M, Hiraki Y, Tsuruyama M, et al. Pharmacokinetics and pharmacodynamics of daptomycin in a clinical setting. Journal of infection and chemotherapy : official journal of the Japan Society of Chemotherapy. 2020 Feb;26(2):230-5.

116. Yamada T, Ooi Y, Oda K, Shibata Y, Kawanishi F, Suzuki K, et al. Observational study to determine the optimal dose of daptomycin based on pharmacokinetic/pharmacodynamic analysis. Journal of infection and chemotherapy : official journal of the Japan Society of Chemotherapy. 2020 Apr;26(4):379-84. 117. Pai MP, Russo A, Novelli A, Venditti M, Falcone M. Simplified equations using two concentrations to calculate area under the curve for antimicrobials with concentrationdependent pharmacodynamics: daptomycin as a motivating example. Antimicrob Agents Chemother. 2014 Jun;58(6):3162-7.

118. Jager NG, van Hest RM, Lipman J, Taccone FS, Roberts JA. Therapeutic drug monitoring of anti-infective agents in critically ill patients. Expert review of clinical pharmacology. 2016 Jul;9(7):961-79. 